anthropology \& materialism

\section{Anthropology \& Materialism}

A Journal of Social Research

$3 \mid 2016$

Utopia: The Elsewhere and The Otherwise

\title{
La trampa de la forma. El regreso de Ferdydurke
}

Gombrowicz, Witold (2014) Ferdydurke. Ciudad Autónoma de Buenos Aires: El Cuenco de Plata

\section{Soledad Nívoli}

\section{(2) OpenEdition}

Journals

\section{Edición electrónica}

URL: http://journals.openedition.org/am/600

DOI: $10.4000 / a m .600$

ISSN: 2364-0480

Editor.

CETCOPRA, CRASSH - Center for Research in the Arts Social Sciences and Humanities, Fakultät Gestaltung - Universität der Künste Berlin

Referencia electrónica

Soledad Nívoli, «La trampa de la forma. El regreso de Ferdydurke », Anthropology \& Materialism [En línea], 3 | 2016, Publicado el 25 noviembre 2016, consultado el 25 julio 2019. URL : http:// journals.openedition.org/am/600 ; DOI : 10.4000/am.600

Este documento fue generado automáticamente el 25 julio 2019.

Tous droits réservés 


\section{La trampa de la forma. El regreso de Ferdydurke}

Gombrowicz, Witold (2014) Ferdydurke. Ciudad Autónoma de Buenos Aires: El Cuenco de Plata

Soledad Nívoli

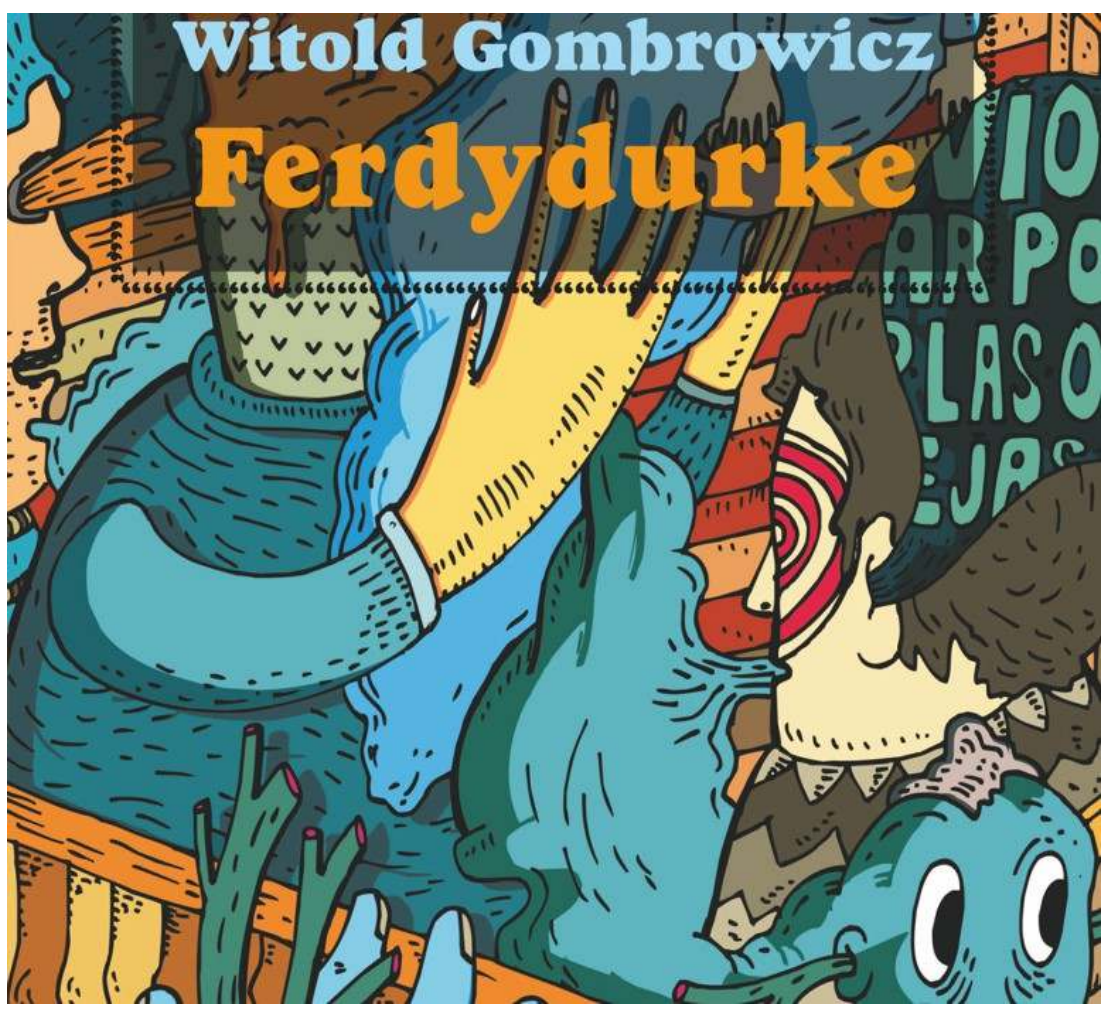

1 El regreso de Ferdydurke a las librerías argentinas representa sólo una parte del retorno del escritor polaco Witold Gombrowicz (Maloszyce, Polonia, 1904 - Vence, Francia, 1969) como autor y como mito. La editorial El Cuenco de Plata ha publicado entre el año 2014 y 2015 otras obras del autor: El casamiento (2014); Curso de filosofía en seis horas y cuarto (2015), Trans-Atlántico (2015), Cosmos (2015) y Bacacay (2015), engrosando su "Biblioteca 
Gombrowicz" y poniendo a disposición de nuevas generaciones de lectores el mundo literario sobresaturado de este escritor polaco que fue, entre otras cosas, argentino por defecto, empleado bancario y anti-borgeano militante.

2 La nueva edición de Ferdydurke, vuelve a poner en circulación una obra cuya historia de vida y traducción sigue siendo tan sorprendente como original. Este libro fue escrito en Polonia en 1937, dos años antes de que Gombrowicz llegara a la Argentina en el transatlántico Chrobry, para quedarse a vivir allí veinticuatro años, hasta 1963. En 1947 se publicó la primera traducción de Ferdydurke en la editorial Argos de Buenos Aires, creación original del encuentro impensado entre un polaco sin conocimientos de la lengua española y varios jóvenes hispanoparlantes sin conocimientos de la lengua polaca. Esta primera versión castellana sirvió a su vez de referencia para la primera edición francesa que el mismo autor junto a otros colaboradores realizó para la editorial Les Lettres nouvelles en 1958' , bajo el pseudónimo de Julliard Brone. En 1968 fue reeditada en Buenos Aires por Sudamericana y recién en el año 2001 fue nuevamente publicada en español por la editorial Seix Barral, sufriendo allí la intervención de correctores que le introdujeron ciertas modificaciones, mínimas pero perceptibles, en la economía de los signos de puntuación que "normalizaban" la fluidez anómala del original.

3 La edición reciente, que coincidió con el aniversario de los setenta y cinco años de la llegada de Gombrowicz a la Argentina y con el multitudinario $\mathrm{I}^{\circ}$ Congreso Internacional organizado en Buenos Aires en agosto del año 2014, tiene el buen tino de desatender las correcciones de la editorial catalana, ateniéndose a la versión de 1947 y respetando la frescura de la creación colectiva de entonces. El lector que se encuentra con ella se verá, en principio, atraído y extrañado por la ilustración de cubierta, Cucucu, realizada por Lucas Ariel Mercado y publicada por primera vez en Esto no es una nariz. Witold Gombrowicz según 40 ilustradores, libro especialmente preparado para el mencionado Congreso. Esta imagen se muestra saturada de colores chillones entre verdes, celestes y naranjas, sedimentada de formas indefinidas, hechas de materia blanda, en las que se reconocen brazos, manos, ojos y orejas perforadas por ramas o frases alusivas. El efecto de esta cubierta es premonitorio. En la saturación de la sensibilidad, en la sensación de fragmentación que produce y en la "violación por las orejas" que escenifica, se adivina la experiencia del lector, ya que todo aquel que atraviese sus páginas quedará implicado en una vivencia que es a la vez la de lo repleto, la de lo parcial y la de lo sin cesar violado.

4 Los escenarios, los personajes y los temas de Ferdydurke podrían corresponder perfectamente con los de cualquier novela de formación (Bildungsroman): un joven en su pequeña pieza de escritor quiere promoverse a los círculos literarios, un grupo de adolescentes en una escuela desafían a sus supervisores y maestros agobiados por la rutina y la pesadez, los miembros de una familia burguesa evalúan al pretendiente de su joven hija, una familia de estancieros recibe a jóvenes citadinos progresistas que buscan confraternizar con peones y criadas. A primera vista, todo debería seguir la dirección del "drama de pasaje" abordado por la literatura psicológica del siglo XIX (Ibsen, Chéjov): las encrucijadas de la mente aún no totalmente esclarecida y los derroteros del alma que vive sumergida en la penumbra de la transición. Pero Gombrowicz produce un pequeño ajuste en la lente de su narración que logra deformar completamente la realidad de ese proceso, generando condiciones atmosféricas que someterán al lector a una dinámica de saturación, fragmentación y violación similar a la que comanda la relación del lector con la obra de arte. Si sus días, como sostiene Gombrowicz en el "Prefacio al Filifor forrado de niño" (uno de los relatos introducidos como cuña en su narración), están llenos de 
estímulos distractivos como una mosca o un llamado telefónico que, despreocupados de su lectura, interrumpen su éxtasis estético, Ferdydurke le ofrece moscas distractivas por doquier, llamados de todo tipo y alusiones marginales de diversa índole que perturban constantemente cualquier acción de pasaje hacia delante, en el sentido del progreso. Así, el joven a punto de promoverse a escritor es raptado por su antiguo supervisor y devuelto a la escuela; el grupo de adolescentes desafiantes en realidad no son más que párvulos a merced de la mirada condescendiente de madres y maestros; la familia progresista pierde su forma ante la intervención del pretendiente que inocula al padre la fuerza incontinente de la risa; la familia de estancieros y los jóvenes progresistas son burlados sin cesar por criadas y peones, a los que necesitan para mantenerse en forma. En cada uno de estos pasajes la intención expresa del autor es, simultáneamente, encontrar el dispositivo mediante el cual expresar la inmadurez, uno de sus más célebres leitmotivs, y desbaratar "la trampa de la forma" (p. 94) mediante exageraciones e interrupciones en el hilo de su historia. Ferdydurke alcanzará ese cometido sólo en la medida en que sus lectores logren abandonarse al dudoso imperio de lo repleto, lo parcial y lo violado; se acomoden a la viscosidad de medias tintas que caracteriza todo estado intermedio y acepten prestar oído al poder creador de las almas medianas (adolescentes, doncellas, semiaclarados semicultos) que posándose en la nuca del vate y violándolo sin cesar, crean desde el exterior y desde abajo un texto que subvierte la forma de la obra, exponiéndola a la monstruosidad de sus componentes.

\section{NOTAS}

1. Según indica Rita Gombrowicz, esposa del escritor polaco y curadora de su obra, la segunda edición de Ferdydurke en Polonia, en 1957, sirvió a su vez de referencia a la segunda traducción francesa, publicada en 10/18 en 1973, y a las versiones en otros idiomas.

\section{AUTOR}

\section{SOLEDAD NÍVOLI}

Doctora en Ciencias Políticas de la Universidad Nacional de Rosario (UNR), Soledad Nívoli imparte la cátedra de «Epistemología » en la Facultad de Psicología de la UNR. Es también profesora en el Instituto Universitario Italiano de Rosario (IUNIR). Actualmente es directora del Centro de Estudios Periferia Epistemológica (CEPE), de la Facultad de Psicología de la UNR. 